\title{
Tecnura
}

http://revistas.udistrital.edu.co/ojs/index.php/Tecnura/issue/view/640

DOI: http://dx.doi.org/10.14483/udistrital.jour.tecnura.2014.SE1.a20

ReFLEXIÓN

\section{La responsabilidad por culpa patronal en el accidente o enfermedad laboral}

\author{
Employer's liability on work accidents or disease
}

\author{
Guillermo Eduardo Alfonso Gutiérrez
}

Citation / Para citar este artículo: Alfonso Gutierrez, G. E. (2014). La responsabilidad por culpa patronal en el accidente o enfermedad laboral. Revista Tecnura, Edición especial, 263-266

Fecha de recepción: 29 de noviembre de 2013 / Fecha de aceptación: 11 de julio de 2014

\begin{abstract}
RESUMEN
El propósito principal de este artículo es abordar los diferentes aspectos de la responsabilidad que conlleva la actividad laboral para el empleador, específicamente aquellos derivados de la generación del accidente de trabajo o la enfermedad laboral, como son los concernientes a la responsabilidad laboral, la cual normalmente es transferida a terceros mediante el pago de aportes (ARL), la administrativa, penal y civil derivada de estos hechos, centrándome en lo concerniente a la responsabilidad civil derivada de la culpa patronal, esto es, de la culpa subjetiva derivada de la acción u omisión patronal que conlleva la generación del accidente de trabajo o la enfermedad laboral, verificando los aspectos generadores de la responsabilidad, así como las consecuencias legales y económicas que se puedan derivar de esta.

Palabras clave: accidente de trabajo, enfermedad laboral, actividad riesgosa, responsabilidad objetiva y subjetiva, dolo, culpa patronal, daño, perjuicios, indemnización.
\end{abstract}

\begin{abstract}
The main purpose of this article is to address the different aspects on the liability that the employer's activity entails, specifically those related to the work accident or disease generation. Some of these responsibilities are usually transferred to a third party by means of contributions payment, destined to organizations of administrative, penal and civil nature. The analysis will be focused on civil responsibility derivative of employers fault, this is, subjective fault derivative of employer action or omission that brings the work accident or disease generation, verifying the aspects generating the liability, as well as the legal and economic consequences that can arise from this.
\end{abstract}

Keywords: work accident, work disease, risky activity, objective and subjective liability, misconduct, employer's fault, harm, damage, compensation.

\footnotetext{
* Abogado Administrativo - laboral e Higiene y Salud Ocupacional, magíster Investigación Social, miembro Comité Nacional de Salud Ocupacional. Contacto: galfonsog@udistrital.edu.co
} 


\section{INTRODUCCIÓN}

La realización de una actividad productiva es esencial para el desarrollo físico y la salud mental de una persona, no obstante son muchas los factores que condicionan la realización de la tarea, tanto físicos (estructurales) como psicosociales, y aunque es innegable su aporte para el desarrollo del ser humano, es también el principal agente causal de múltiples molestias y enfermedades (Daza, 2010).

Es responsabilidad del empleador "proporcionar y mantener ambientes y condiciones de trabajo saludables y proteger la salud de los trabajadores de cualquier daño que se produzca por causa o con ocasión del trabajo" (Tafur, 2008), pero es también responsabilidad de los trabajadores seguir los procesos según lo estipulado por la organización y desarrollar sus tareas con base en la capacitación otorgada por la empresa contratante.

No obstante, cuando por alguna razón ocurre un accidente de trabajo o se le diagnostica a un trabajador una patología considerada como de origen laboral, a pesar de encontrarse este afiliado a una entidad Administradora de Riesgos Laborales, debe determinarse si el empleador no brindó al trabajador las garantías mínimas requeridas para llevar a cabo su actividad laboral de manera segura, y por tanto puede señalarse como "culpable" del fenómeno adverso evidenciado en el trabajador, con lo cual deberá "responder" frente al daño causado al trabajador.

En el desarrollo del escrito se presentarán la evolución del concepto, impacto en el manejo que se da a las eventualidades en salud que se presentan en los trabajadores consideradas como resultado de la mala gestión de sus empleadores y aplicación de la norma a la cotidianidad de los trabajadores, con el objetivo de brindar un panorama general acerca de la responsabilidad por culpa patronal en accidentes de trabajo y enfermedad laboral (ATEL) en la población trabajadora.

\section{DEFINICIÓN DEL CONCEPTO}

Es indispensable comenzar por el desglose del concepto tratado, para llegar a comprender de manera concreta lo concerniente a responsabilidad por culpa patronal en el accidente de trabajo y la enfermedad laboral.

En primera instancia se debe entender que existe como tal la figura de contratante y contratista cuando se establece un contrato de trabajo que se define como el "acuerdo entre dos partes, empresario y trabajador, por el que este último queda obligado a prestar un servicio por cuenta y bajo la dirección y organización del empresario, a cambio de una retribución" (Aguilar, 2010). Pero aunque en la definición solo se especifica el contexto laboral, aquí tambien es fuente de responsabilidad la relación contratante y contratista, en el entendido que esta puede conllevar en el trato subordinante la figura de un contrato realidad, al tenor de lo expresado en el artículo 53 de la Constitución Política de Colombia, respecto de la primacia de la realidad sobre las formas en el contrato laboral, con lo que queda fijado el compromiso generado para el trabajador, pero debe entenderse que el empleador también asume un compromiso con este, ello sin contar que en la defiinición de accidente laboral esta obligación tambien se extiende al contratante en una relación de contrato civil de prestación de servicios, el cual consiste en desarrollar un Sistema de Gestión de Salud y Seguridad en el Trabajo, anteriormente denominado programa de salud ocupacional cuyo objeto es "anticipar, reconocer, evaluar y controlar los riesgos que puedan afectar la seguridad y la salud en el trabajo." (Ministerio De Trabajo De Colombia, 2014), como se encuentra claramente especificado en el artículo cuarto del Decreto 1443 de 2014.

En la formulación de esta resolución se pone en evidencia la responsabilidad que tiene el contratante de poner a disposición de las personas que se encuentran bajo su subordinación laboral, los mecanismos, herramientas y procesos necesarios para que la tarea realizada no represente daño a 
nivel físico, mental o moral y que por el contrario, fomente los factores protectores de la salud en la vida del sujeto. Sin embargo, no puede obviarse la realidad de mundo laboral, puesto que existen múltiples factores de riesgo con potencialidad de generar daño a las personas, incluso en algunas ocasiones la tarea en sí misma es una actividad que puede clasificarse como peligrosa.

Cuando uno de estos factores de riesgo ocasiona eventualidades negativas en la salud del trabajador y surge un accidente de trabajo que se considera como "todo suceso repentino que sobrevenga por causa o con ocasión del trabajo, y que produzca en el trabajador una lesión orgánica, una perturbación funcional o psiquiátrica, una invalidez o la muerte. Es también accidente de trabajo aquel que se produce durante la ejecución de órdenes del empleador, o contratante durante la ejecución de una labor bajo su autoridad, aún fuera del lugar y horas de trabajo. Igualmente se considera accidente de trabajo el que se produzca durante el traslado de los trabajadores o contratistas desde su residencia a los lugares de trabajo o viceversa, cuando el transporte lo suministre el empleador. También se considerará como accidente de trabajo el ocurrido durante el ejercicio de la función sindical aunque el trabajador se encuentre en permiso sindical siempre que el accidente se produzca en cumplimiento de dicha función. De igual forma se considera accidente de trabajo el que se produzca por la ejecución de actividades recreativas, deportivas o culturales, cuando se actúe por cuenta o en representación del empleador o de la empresa usuaria cuando se trate de trabajadores de empresas de servicios temporales que se encuentren en misión." (Congreso De La República De Colombia, 2012) o se diagnostica una enfermedad laboral la cual "Es la contraída como resultado de la exposición a factores de riesgo inherentes a la actividad laboral o del medio en el que el trabajador se ha visto obligado a trabajar. El Gobierno Nacional determinará, en forma periódica, las enfermedades que se consideran como laborales y en los casos en que una enfermedad no figure en la tabla de enfermedades laborales, pero se demuestre la relación de causalidad con los factores de riesgo ocupacional será reconocida como enfermedad laboral, conforme lo establecido en las normas legales vigentes." (Congreso De La República De Colombia, 2012), en principio en el ámbito laboral, teniendo en cuenta que en nuestra legislación en materia de responsabilidad laboral estos criterios obedecen al concepto de responsabilidad objetiva o responsabilidad profesional, tarifada y delegada por el empleador en un tercero "Administradoras de Riesgos Laborales (ARL)", son estos los inicialmente llamados a responder por el daño laboral resultado de una de estas contingencias; sin embargo, se debe identificar no para la determinación en sí del accidente de trabajo o para la enfermedad laboral, si hay un nexo que involucre al patrón como responsable de la generación de estos, sea por exceso o defecto en las acciones suscitadas que hayan ocasionado deterioro en la salud del trabajador, con lo cual se determinara la responsabilidad por culpa patronal por la que deba responder frente al daño causado en la persona del trabajador.

Pero, ¿qué puede denominarse responsabilidad? Si se analiza el término simplemente, sin correlacionarlo con la situación específica, se refiere al hecho de asumir las consecuencias de los actos llevados a cabo, reconocer que las actividades efectuadas generan implicaciones en la vida de otras personas y en el ambiente en que se desenvuelven. Abordando el tema de las organizaciones se entiende que la empresa debe tomar en cuenta que sus actividades afectan, positiva o negativamente, la calidad de vida de sus empleados y de las comunidades en las que realiza sus operaciones. Recientemente se ha convertido en una nueva forma de gestión y de hacer negocios, en la cual la empresa se ocupa de que sus operaciones sean sustentables en lo económico, lo social y lo ambiental, reconociendo los intereses de los distintos grupos con los que se relaciona y buscando la preservación del medio ambiente y la sustentabilidad de las generaciones futuras. Es una visión de negocios que integra el respeto por las personas, los 
valores éticos, la comunidad y el medio ambiente con la gestión misma de la empresa, independientemente de los productos o servicios que esta ofrece, del sector al que pertenece, de su tamaño o nacionalidad (Cajiga, 2008).

Llegando de esta manera deductiva al tema de discusión que atañe el actual escrito, la responsabilidad por culpa patronal en el accidente de trabajo y enfermedad laboral en el trabajador, se define esta como la comprobación del nexo de culpa del empleador en la ocurrencia de ATEL (Congreso De La República De Colombia, 2011).

Retomando la totalidad de los conceptos desde el inicio de este acápite, se resumiría que el empleador, debido a la relación contractual que establece con una persona y la obligatoriedad que posterior a la creación de este nexo le demanda ofrecer al trabajador un ambiente propicio para el desarrollo de las actividades laborales en forma segura, conlleva que la aparición de consecuencias adversas en la salud del trabajador con causa u ocasión del trabajo, deben ser investigadas y establecerse si existe culpabilidad o no por parte del patrono en dicho fenómeno. De ser demostrado el nexo de culpa por parte de este último, implica el deber de responder tanto a nivel personal como organizacional por la impertinencia de sus acciones sea por defecto o exceso, generándole el compromiso de resarcir al empleado los perjuicios causados según establece la ley.

\section{NORMATIVIDAD EN LA DETERMINACIÓN DE RESPONSABILIDAD POR CULPA PATRONAL EN ATEL}

El empleador adquiere unos compromisos legales concretos con el trabajador, posteriormente al establecimiento del contrato laboral. En lo relacionado con la seguridad y salud en el trabajo pueden mencionarse los respectivos a la afiliación obligatoria al sistema general de riesgos laborales (SGRL) (Ministerio Del Trabajo y Seguridad Social, 1994), desarrollo obligatorio de un sistema de gestión de seguridad y salud en el trabajo (SGSST) formulado en el Decreto 1443 de 2014, que remplazó el antiguo Programa de Salud Ocupacional determinado en la resolución 1016 de 1989, la prevención del accidente de trabajo y la enfermedad laboral expresados en los artículos 3 y 4 de la ley 1562 de 2012 (Congreso De La República De Colombia, 2012) y lo promulgado en el artículo 11 de la Decisión 584 Instrumento Andino de Seguridad y Salud en el Trabajo, "En todo lugar de trabajo se deberán tomar medidas tendientes a disminuir los riesgos laborales. Estas medidas deberán basarse, para el logro de este objetivo, en directrices sobre sistemas de gestión de la seguridad y salud en el trabajo y su entorno como responsabilidad social y empresarial" (Consejo Andino De Naciones, 2004).

De esta normatividad surge la responsabilidad del empleador con el trabajador a diferentes niveles: responsabilidad laboral, responsabilidad civil, responsabilidad penal y responsabilidad administrativa (Tafur, 2008), responsabilidades estas que tienen sus propias características, así:

\section{Responsabilidad laboral}

Surge del contrato de trabajo.

- Responsabilidad delegada del empleador a una ARL, mediante el pago de la cotización mensual.

- El monto de la indemnización es tarifado.

- El beneficio del trabajador y/o su familia como consecuencia del ATEL se ve representado mediante prestaciones económicas y asistenciales, subsidio, indemnización, pensión y pensión de sobrevivientes.

- El origen de la invalidez por ATEL y su apelación lo determina en su orden: la EPS, Fondos de Pensiones, las ARL, la Junta Regional de Calificación de Invalidez o la Junta Nacional de Calificación de invalidez.

- La prescripción de las prestaciones es de tres años.

- No existe el caso fortuito o fuerza mayor que exonere la responsabilidad de la ARL en el accidente ni la culpa grave de la víctima, por ser esta de responsabilidad objetiva.

- No importa que el vínculo laboral termine. 
- El pago de las cotizaciones cubre también a contratistas de actividades consideradas peligrosas a cargo del contratante.

- Los trabajadores independientes pueden asegurarse pagando el monto de la cotización exigida para el tipo de riesgo al que estén expuestos.

\section{Responsabilidad civil}

Surge de la relación contractual, al tenor de lo determinado en el art. 216 del Código Sustantivo de Trabajo, "Cuando exista culpa suficiente comprobada del \{empleador\} en la ocurrencia del accidente de trabajo o de la enfermedad profesional, está obligado a la indemnización total y ordinaria por perjuicios pero del monto de ella debe descontarse el valor de las prestaciones en dinero pagadas en razón de las normas consagradas en este Capítulo". (Congreso De La República De Colombia, 2011) Corresponde a la responsabilidad Aquiliana o responsabilidad civil puramente dicha. En el caso de que el empleador sea el Estado surge de lo determinado en el artículo 90 de la Constitución Política: "El Estado responderá patrimonialmente por los daños antijurídicos que le sean imputables, causados por la acción o la omisión de las autoridades públicas. En el evento de ser condenado el Estado a la reparación patrimonial de uno de tales daños, que haya sido consecuencia de la conducta dolosa o gravemente culposa de un agente suyo, aquél deberá repetir contra éste". (Asamblea Nacional Constituyente, 1991). Y en el artículo 140 del Código Contencioso Administrativo.

- Responsabilidad asumida directamente por el empleador, con posibilidad de repetición cuando es entidad estatal, de acuerdo a lo determinado en el artículo 142 del Código Contencioso Administrativo.

- El monto de los daños no se encuentra tarifado, este depende de los perjuicios causados al trabajador o a sus beneficiaros.

- Los perjuicios o daños causados al trabajador corresponden a materiales, morales, fisiológicos y los correspondientes al daño de relación.
- El daño o perjuicio causado se "pretende" remediar mediante el pago pecuniario (salarios mínimos legales mensuales vigentes : moral).

- El proceso de demanda y apelación en su orden se realiza ante la justicia laboral ordinaria.

- El empleador puede eximirse de su responsabilidad demostrando culpa exclusiva de la víctima, caso fortuito o fuerza mayor ajena al empleador y su actividad.

- Prescribe a los tres años la acción.

- No puede descontar lo que le da la ARL.

\section{Responsabilidad penal}

Surge del titular del delito causado al afectado (personalizado).

- Responsabilidad asumida por el causante del hecho punible (empleador, especialista en salud ocupacional, miembros de la Junta de calificación de invalidez, funcionario de la ARL o trabajador).

- La responsabilidad aquí se genera por culpa, por dolo o preterintención en el ATEL, con lo cual se debe determinar los postulados de tipicidad, daño al bien jurídico tutelado y culpabilidad que corresponden a un delito.

- El proceso penal se cumple ante el juez penal correspondiente, mediante el sistema oral acusatorio que se maneja en la jurisdicción penal colombiana, como ente acusador actúa la Fiscalía General de la Nación.

- La clase de delitos que pueden surgir de la responsabilidad penal en el ATEL: delitos contra la vida, delitos contra la fe pública, delitos contra la administración pública.

\section{Responsabilidad administrativa}

Surge de la función legal de vigilancia y control en Salud Ocupacional, que correponde en materia laboral al Ministerio de Trabajo y en materia de imposición de multas a la Superintendencia Bancaria. 
- Se impone multa que es asumida por el empleador por no afiliación a riesgos y no cumplir normas en Salud Ocupacional, de 500 salarios mínimos mensuales, por reporte extemporáneo del ATEL de 200 salarios mínimos mensuales, por ocultar información que altere el índice de lesiones incapacitantes ILI hasta 1.000 salarios minimos, por ocultar o falsificar información sobre accidente mortal hasta 1.000 salarios minimos legales.

- La sanción o multa a favor del fondo de Riesgos Profesionales.

- Existen multas para el empleador y las ARL.

- Se imponen además de las multas, cierres temporales o permanentes de la empresa por hechos graves que puedan poner en peligro a los trabajadores.

- La competencia para vigilar y controlar la administración del sistema de prevención de las ARL es del Ministerio de la Protección Social. La de la prestación de servicios de salud es de Supersalud.

- Por dilatar el pago de prestaciones económicas corresponde a la Superfinanciera el cobro de las multas.

La responsabilidad por culpa patronal en los accidentes de trabajo o en las enfermedades de origen laboral corresponde al concepto de responsabilidad contractual y/o extracontractual determinada en el Código Civil colombiano, en los artículos 2341 y subsiguientes, que corresponde al concepto romano de culpa aquiliana, en donde se determina "El que ha cometido un delito o culpa, que ha inferido daño a otro, es obligado a la indemnización, sin perjuicio de la pena principal que la ley imponga por la culpa o el delito cometido" (Tafur, G., 2012), y de aquí se deriva que esta responsabilidad corresponde a la imputación subjetiva, ya que de allí se deriva un factor de atribución, porque se refiere al análisis de la conducta del sujeto reclamado, determinando si cabe alguno de los factores de atribución a la conducta del sujeto frente al hecho, esto es, la relación de la acción u omisión como hecho generador con el sujeto, con el fin de configurar los elementos de la responsabilidad civil como son: los sujetos, el hecho generador, la posibilidad de imputar (factor de atribución), el nexo causal y el daño; así las cosas, la responsabilidad puede ser de tipo "Dolosa - La conducta es dolosa cuando el agente conoce el hecho punible y quiere su realización, lo mismo cuando la acepta previéndola al menos como posible", por "Culpa - La conducta es culposa cuando el agente realiza el hecho punible por falta de previsión del resultado previsible o cuando habiéndolo previsto, confió en poder evitarlo" o por "Preterintención-La conducta es preterintencional cuando su resultado, siendo previsible, excede la intención del agente." (Congreso De La República De Colombia, 1999).

En el caso del empleador generalmente incurre en culpa patronal, por lo que para la determinación de esta se debe tener en cuenta los factores generadores de la culpa, los cuales se generan por:

- Negligencia, Es el descuido u omisión, la falta de cuidado o interés al desempeñar una obligación (Real Academia De La Lengua Española, 2013), es cuando no cumple con las normas o leyes en Salud Ocupacional, no se toman las medidas preventivas (mantenimientos preventivos y correctivos en equipos, no se proporcionan elementos de protección adecuados y la no capacitación del trabajador).

- Imprudencia, corresponde a aquella falta de juicio, sensatez y cuidado que una persona demuestra en sus acciones (Real Academia De La Lengua Española, 2013) porque se obra mal, sin cautela y sin prever los resultados o consecuencias de una acción.

- Impericia, es la ineptitud o incapacidad técnica para ejercer una profesión o un oficio, por ignorancia (Real Academia De La Lengua Española, 2013), error e inhabilidad, entendiéndose esta como falta de destreza para hacer las cosas.

- Violación de los reglamentos y/o normas, cuando se ignoran o violan los reglamentos o normas de salud ocupacional. 
La responsabilidad por culpa patronal en el ATEL debe ser probada por el empleado afectado, aunque en la enfermedad laboral hay unos lineamientos determinados. El solo incumplimiento del antes Ilamado programa de salud ocupacional, o como se denomina actualmente en la ley 1562 de 2012, Sistema de Gestión en Salud y Seguridad en el Trabajo, hacen culpable al empleador de los eventos que causen alteraciones en la salud del trabajador dentro del cumplimiento de sus tareas laborales.

\section{Pago de indemnización total y ordinaria por perjuicios en ATEL}

El pago de indemnizaciones está normado en el Código Sustantivo del Trabajo, Art. 216, en el cual se afirma que "Cuando exista culpa suficiente comprobada del patrono en la ocurrencia del accidente de trabajo o en la enfermedad laboral, está obligado a la indemnización total y ordinaria por perjuicios, (...) (Congreso De La República, 2011)."

A continuación se expone lo que significa la indemnización total y ordinaria de perjuicios:

"Esta responsabilidad contractual nace de la existencia del contrato de trabajo por el incumplimiento del deber de protección y seguridad que tiene el empleador con su trabajador, los cuales, a su vez, le demandan tomar las medidas adecuadas, atendiendo las condiciones generales y especiales del trabajo, tendientes a evitar que aquél sufra menoscabo de su salud o integridad a causa de los riesgos del trabajo" (Sentencia Ref. 22656, 2005). Es de aclarar aquí que la Corte Suprema de Justicia ha determinado que cuando el empleador desarrolla actividades consideradas como peligrosas, esta responsabilidad es subjetiva, toda vez que el ejecutor se hace responsable y debe resarcir el daño causado, sin que se requiera prueba de la culpa, no en virtud propia de una presunción, sino porque esta no es necesaria para probar la existencia de la realidad; con esto la Corte determino que a pesar de haber actividades ejecutadas sin intención de causar daño, ni ocultas o torcidas, e incluso sin culpa, el solo carácter de riesgo que conlleva la actividad lo obliga a resarcir los daños causados; es así como señala que nace de la "presunción rotunda" de que el agente obró con la imprevisión propia de la culpa, que se enmarca en el artículo 2356 del Código Civil, y así las cosas, en este caso la víctima no está obligada a demostrar la culpa, sino que debe establecer el daño y el nexo causal y en este caso, el responsable solo podrá exonerarse mostrando que existió caso fortuito, fuerza mayor, culpa exclusiva de la víctima o la intervención de un tercero. (Sentencia 47001310300320050061101, 2010).

La indemnización se debe llevar a cabo según dicta la norma, artículos 1613 y 1614 del Código Civil:

\section{Indemnización total y ordinaria de perjuicios.}

Esta reparación ha de comprender tanto los perjuicios patrimoniales como los extra patrimoniales:

\section{Perjuicios patrimoniales o materiales}

Dentro de los perjuicios patrimoniales o materiales se tiene:

Daño emergente, que corresponde al perjuicio o la pérdida que proviene de no haberse cumplido la obligación o de haberse cumplido imperfectamente, o de haberse retardado su cumplimiento (Tafur, G., 2012):

a) Daño emergente pasado. Es el derecho que tiene toda víctima a que se le reembolse todos los gastos razonables en que haya incurrido con ocasión a la ocurrencia del hecho y hasta el momento en que el deudor los cancele o cuando el Juez dicte sentencia.

b) Daño emergente futuro. Son los gastos que a futuro va a tener que sufragar la víctima en razón de la lesión.

Lucro cesante, que corresponde a la ganancia o provecho que deja de reportarse a consecuencia de no haberse cumplido la obligación, o cumplido imperfectamente, o retardado su cumplimiento (Tafur, G., 2012). 
(Cuando un bien económico que debía ingresar en el curso normal de los acontecimientos no ingresó ni ingresará en el patrimonio de la víctima).

a) Lucro cesante consolidado. Es aquel nacido de la limitación para dedicarse a labores útiles que significaban para él un provecho liquidado hasta la fecha de la sentencia. La primera tarea del fallador consiste en determinar el ingreso laboral mensual promedio que tenía la víctima en el momento de ocurrir la lesión. El paso siguiente es actualizar monetariamente el valor de dicho ingreso para finalmente obtener el valor del lucro cesante pasado.

b) Lucro cesante futuro. Se determina desde la fecha de la sentencia hacia el futuro y corresponde al valor de la limitación a aquellas actividades que desarrollaba la víctima y que le representaba provecho. Se toma como base el salario mínimo mensual que en el momento de efectuar la liquidación estaría devengando la víctima si no hubiera sufrido la lesión. Con ello se busca dejar a la víctima en las mismas condiciones en que se encontraba al ocurrir el hecho lesivo. "Indemnización por reposición o reemplazo".

\section{Perjuicios extra patrimoniales o morales}

Este tipo de perjuicio tiene un límite marcado por la Corte Constitucional en Mil Salarios Mínimos Legales Mensuales Vigentes, esto es, \$589.600.000, pero ha sido limitado por reiteradas Sentencias de la Corte Suprema de Justicia en máximo 200 SMLMV, que equivalen para el año 2013 a $\$ 117.920 .000$ para cada beneficiario del mismo.

La indemnización por perjuicios morales subjetivos busca remediar en parte no solo las angustias y depresiones producidas por el hecho lesivo, sino también el dolor físico que en un momento determinado pueda sufrir la víctima de un accidente o enfermedad laboral.

\section{Perjuicios fisiológicos o perjuicios a la vida de relación}

Este tipo de perjuicio es una supresión de las actividades vitales, placenteras y de relación con los semejantes y/o con las cosas del exterior, con lo que la reparación de este daño lo que repara es la pérdida de la posibilidad de realizar otras actividades vitales, que, aunque no producen rendimiento patrimonial hacen agradable la existencia. (Sentencia Rad. 7428, 1993).

Referente a la indemnización que corresponda por este tipo de daño, teniendo en cuenta que no existe un criterio definido para el mismo, corresponde a quien reclame este tipo de daño probarlo en su existencia y en el monto del mismo, pero siempre será el juez quien en forma autónoma y soberana determine si efectivamente se ha generado el mencionado daño, así como el monto de los perjuicios causados, decisión que se tomará con apoyo del dictamen medico - legal que se profiera para cada caso en particular.

\section{REFLEXIONES FINALES}

En la actualidad debido a la globalización y la competencia entre industrias, donde en ocasiones la oferta es superior a la demanda, se olvida a los seres humanos que están detrás del producto y que trabajan incansablemente para satisfacer el consumo. Afortunadamente con el transcurrir de las décadas han surgido normas para proteger a los trabajadores, haciendo que se vislumbre la luz al final del túnel; no hay excusas para evitar la adherencia a la normatividad, puesto que ni siquiera el desconocimiento de la ley justifica el incumplimiento de la misma, como es descrito en el Código Civil colombiano en su Artículo 9, el cual cita que "La ignorancia de las leyes no sirve de excusa", artículo que fue declarado EXEQUIBLE por la Corte Constitucional, mediante Sentencia C-651-97 del 3 de diciembre de 1997, "es necesario exigir de cada uno de los miembros de la comunidad que se comporte como si conociera las leyes que tienen que ver con su conducta. La obediencia al derecho no puede dejarse a merced de la voluntad de cada uno, pues si así ocurriera, al mínimo de orden que es presupuesto de la convivencia comunitaria, se sustituiría la anarquía que la imposibilita." 
A pesar de ello, en pleno siglo XXI se evidencian condiciones infrahumanas para desarrollar las actividades laborales, y el incumplimiento de la normatividad en su máxima expresión al evitar afiliar al Sistema de Seguridad Social y al Sistema de Riesgos Laborales a los trabajadores, lo cual ha traído como consecuencia que en la práctica se presenten enfermedades de origen laboral y accidentes de trabajo que se consideran como prevenibles y que dejan como conclusión que todavía se obvian las responsabilidades para garantizar los derechos a la vida y la integridad personal en el trabajo.

Es obligación de todo empleador afiliar a todo su personal a un Sistema de Seguridad Social y de Riesgos Laborales, el cual garantice una atención integral a los trabajadores en caso de presentarse un accidente de trabajo o enfermedad de origen laboral; este precepto está basado en la teoría de la responsabilidad objetiva, con lo cual se garantiza al trabajador la adecuada atención y el pago de las prestaciones sociales laborales, pero esta obligación del empleador no solo se limita a afiliar a los trabajadores al sistema, sino también la de garantizar la prevención y controlar los factores de riesgo laboral que genere su actividad. Todo empleador está en la obligación de cumplir todas las leyes, decretos y normativas del sistema de Seguridad Social en Riesgos Laborales, por ende el empleador debe tomar las medidas de seguridad necesarias y requeridas para proteger la salud e integridad de sus trabajadores; dicha afirmación crea entonces una responsabilidad frente al trabajador, la cual nace de la existencia del contrato de trabajo, que pasa del plano objetivo al de la responsabilidad subjetiva del empleador, donde podrá asignársele las culpas respectivas frente al daño generado a un trabajador, la Corte Suprema de Justicia ratifica que a pesar de que el empleador se encuentre afiliado y al día en cotizaciones con la Administradora de Riesgos Profesionales, tendrá que asumir el pago de prestaciones adicionales a las contenidas en las normas de Seguridad Social cuando no haga gestión de prevención de accidentes y enfermedades profesionales, o cuando el desarrollo de los programas de Salud Ocupacional, Higiene y Seguridad Industrial es adelantado por personas no competentes; en este caso la acción punitiva es extensiva al profesional que realiza una inadecuada asesoría, por vía de la figura del Ilamamiento en garantía estipulada en el Código Civil Colombiano, y de igual forma habrá lugar a responsabilidad solidaria cuando exista entre contratante y contratistas identidad de negocio, tal como lo determina el artículo 34 del Código Sustantivo del Trabajo.

Aunque en la normatividad se encuentre estipulada claramente la responsabilidad que el empleador tiene con su trabajador, en la realidad se evidencia lo contrario. La reacción de las organizaciones ante la ocurrencia de un accidente de trabajo es asignar al error humano por parte del trabajador, como única causa del hecho adverso sin tener en cuenta los factores de riesgo que el empleador ha propiciado en los lugares de trabajo. Las ARL, por su lado, también buscan la forma de evadir la responsabilidad y es de esta forma como se encuentra al trabajador afectado en un máximo estado de vulnerabilidad, sin ayuda de las entidades que por convicción y no por temor a la ley deberían protegerlo.

Aunque aún se dista mucho del cumplimiento de las garantías para el desarrollo de las actividades laborales por parte de las personas en los diferentes sectores productivos, es importante reconocer que la normatividad ha dado pasos importantes para la consecución de unos mínimos exigibles y dignificación de las condiciones de trabajo. En la medida en que la sociedad madure, podrá comprender que la protección al trabajador es la protección misma de la sociedad, pues todos cumplimos con este rol independientemente de la ubicación piramidal dentro de la organización. "El que da, recibe" y generar a los trabajadores condiciones adecuadas para el desarrollo de sus tareas, es más impactante al nivel productivo que cualquier otra estrategia de mercadeo. Ojalá pronto se entienda en este modelo de sociedad capitalista. 


\section{FINANCIAMIENTO}

\author{
Recurso propio
}

\section{REFERENCIAS}

Aguilar, J. E. (2010). El contrato de Trabajo. Recuperado el 26 de abril de 2013, de: Network de Psicología Organizacional: www.conductitlan.net/psicologia_organizacional/contratos_de_trabajo.pdf

Asamblea Nacional Constituyente (1991). Constitución Política de Colombia. Art. 90. Recuperado el 26 de abril de 2013, de: Presidencia de la República de Colombia: http://wsp.presidencia.gov.co/Normativa/Documents/Constitucion-Politica-Colombia.pdf

Cajiga, J. F. (2008). El concepto de Responsabilidad social empresarial, pp. 2-3. Recuperado el 26 de abril de 2013, de: cemefi: http://www.cemefi.org/esr/ images/stories/pdf/esr/concepto_esr.pdf

Congreso De La República De Colombia (2011). Artículo 216, Código Sustantivo del Trabajo. Recuperado el 23 de abril de 2013, de: OIT: http://www.ilo.org/ dyn/travail/docs/1539/Codigo\%20Sustantivo $\% 20$ del\%20Trabajo\%20Colombia.pdf

Congreso De La República De Colombia (1999). Ley 599 de 1999, Código Penal Colombiano, Arts. 22, 23, 24. Recuperado el 23 de abril de 2013, de: vlex: http://legislacion.vlex.com.co/vid/codigo-penal-42846002?_ga=1.177605856.456073723.141 5224591

Congreso De La República De Colombia (2012). Ley 1562 de 2012, Arts. 3 y 4. Recuperado el 26 de abril de 2013, de: Presidencia de la República: http://wsp.presidencia.gov.co/Normativa/Leyes/ Documents/ley156211072012.pdf

Consejo Andino De Naciones (2004). Desición 584, Instrumento Andino de Seguridad y Salud en el Trabajo. Recuperado el 26 de abril de 2013, de: Consejo Andino del Ministerio de Relaciones Exteriores: http://www.mintra.gob.pe/contenidos/archivos/sst/decision_584.pdf
Daza, F. M. (2010). NTP 443 Factores psicosociales: Método de evaluación. Recuperado el 26 de abril de 2013, de: INSHT Instituto Nacional de Higiene y Seguridad en el Trabajo: www.insht.es/InshtWeb/ Contenidos/Documentacion/FichasTecnicas/NTP/ Ficheros/401a500/ntp_443.pdf

Ministerio De Trabajo De Colombia (31 de julio de 2014). Decreto 1443 de 2014. Recuperado el 03 de noviembre de 2014, de: Ministerio del trabajo: www.mintrabajo.gov.co/component/docman/doc_ dowload/2095-decreto1443sgsss.html

Ministerio Del Trabajo Y Seguridad Social (1994). Decreto 1295 de 1994 Por el cual se determina la organización y administración del Sistema General de Riesgos Profesionales. Recuperado el 26 de abril de 2013, de: Ministerio de Gobierno de la República de Colombia: http://copaso.upbbga.edu.co/legislacion/Decreto\%20ley\%201295\%20de\%2094\%20 Sistema\%20General\%20de\%20Riesgos\%20Profesionales.pdf

Real Academia De La Lengua Española (2013). Diccionario Español. Recuperado el 26 de abril de 2013, de: RAE: http://www.rae.es/

Sentencia 47001310300320050061101, 47001310300320050061101 (Sala Laboral, 26 de agosto de 2010). Obtenido de: https://relatorestematicos.uniandes.edu.co/images/stories/relatorias/ pdfs/responsabilidadcivil/actividadespeligrosaspresuncionculpa26agosto2010.pdf

Sentencia Rad. 7428, Rad. 7428 (Consejo De Estado, 6 de mayo de 1993).

Sentencia Ref. 22656, Sentencia Ref. 22656 (Sala Laboral, 30 de junio de 2005). Obtenido de: http://www. arlsura.com/images/stories/sentencia_22656_30_ junio_2005.pdf

Tafur, G. A. (2012). Código Civil Colombiano, Artículos 1614 y 2341. Bogotá, D. C.: Leyer Ltda.

Tafur, J. F. (2008). Obligaciones y Responsabilidades en el Sistema General de Riesgos Profesionales . Recuperado el 27 de abril de 2013, de: Consejo Superior de la Judicatura: www.ramajudicial.gov.co

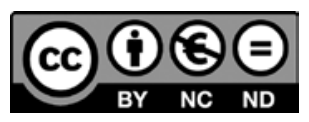

Tecnura • p-ISSN: 0123-921X • e-ISSN: 2248-7638・ Edición especial 2014 • pp. 263-266 